\title{
Feminismo, gênero e religião - os desafios de um encontro possível ${ }^{*}$
}

\author{
Maria José Rosado**
}

\section{Resumo}

Estudiosas/os da temática "gênero e religião" apontam para o difícil encontro destes estudos com aqueles realizados na área da Ciência da Religião. Sublinham que estados da arte sobre a produção brasileira relativa às religiões não mencionam a temática de gênero ou feminismo enquanto, de modo similar, os balanços na área de estudos de gênero deixam de contemplar a produção acadêmica no campo da Ciência da Religião. $\mathrm{O}$ artigo trabalha resultados de pesquisa a respeito dessa dupla invisibilidade, analisando os programas de pós-graduação, grupos de pesquisa e periódicos brasileiros das duas áreas. Os principais achados sinalizam que o distanciamento entre os dois campos - Ciência da Religião e Gênero - pode decorrer da escassez de interação entre acadêmicas/os, o que se revela nos assuntos escolhidos para a pesquisa, na avaliação institucional pelos pares que se processa em diferentes subcomissões e no vínculo que estabelecem com Instituições de Ensino Superior (IES) de caráter confessional ou leigo.

Palavras-chave: Feminismo. Gênero. Institucionalização dos estudos de gênero. Institucionalização dos estudos de religião. Ensino superior confessional.

\section{Feminism, gender and religion - the challenges of a possible encounter}

\begin{abstract}
Women and men, scholars of "gender and religion" point to the difficult encounter of these studies with those made in the area of religious studies. They point out that the state of the art on the Brazilian production on religions do not mention the issue

* O presente artigo resulta de projeto apoiado pelo CNPq, por meio de bolsa de produtividade em pesquisa e de projeto realizado pelo GREPO - grupo de pesquisa Gênero, Religião e Política.

** Socióloga, doutora em Ciências Sociais pela EHESS / Paris, professora do Programa de Pós-Graduação em Ciência da Religião da Pontifícia Universidade Católica de São Paulo, pesquisadora I do CNPq, e coordenadora do grupo Gênero, Religião e Política (GREPO). Integrante da ONG Católicas pelo Direito de Decidir. mjrosado@uol.com.br
\end{abstract}


of gender and feminism while, similarly, the texts in the field of gender studies do not foresee the academic production in the field of religious studies. The article works research results on this double invisibility, analyzing graduate programs, research groups and Brazilian journals of the two areas. The mainfindings indicate that the gap between the two fields of research - Religious Studies and Gender - may result from the lack of interaction between academics. This can be seen in the subjects chosen for research, in the institutional evaluation by peers that takes place in different sub-committees and in the link established with higher education institutions of confessional or lay character. Key-words: Feminism. Gender. Institutionalization of gender studies. Institutionalization of religious studies. Higher education institutions.

\section{Feminismo, género y religión - los desafíos de un posible encuentro}

\section{Resumen}

Mujeres y hombres, estudiosos de "género y religión" señalan el difícil encuentro de aquellos estudios con los que se hacen en el área de estudios de religión. Señalan que el estado del arte sobre la producción brasileña sobre las religiones no menciona el tema del género y el feminismo, mientras que los textos del campo de los estudios de género no contemplan la producción académica en el campo de los estudios de religión. El artículo trabaja los resultados de una investigación sobre esta doble invisibilidad, analizando programas de posgrado, grupos de investigación y revistas brasileñas de las dos áreas. Las principales conclusiones indican que la brecha entre los dos campos de investigación - estudios de religión y de género - puede resultar de la falta de interacción entre las/los académicas/os. Esto se puede ver en los temas elegidos para la investigación, en la evaluación institucional por pares que tiene lugar en diferentes subcomités y en el vínculo establecido con las instituciones de educación superior de carácter confesional o laico.

Palabras clave: Feminismo. Género. Institucionalización de los estudios de género. Institucionalización de los estudios de religión. Instituciones de educación superior.

\section{Introduzindo a questão}

Agradeço, em primeiro lugar, o voltar à UMESP, sempre uma alegria para mim. ${ }^{1}$

Talvez o título desta conversa devesse terminar com uma interrogação e não com um ponto final. Será mesmo possível um encontro entre feminismo e religião? Noto, logo de início, que uso religião, no singular, entendendo aqui, tratar-se das religiões, em sua realização histórica e em sua diversidade, ainda que o horizonte do texto seja o cristianismo, hegemônico no Ocidente.

1 Aula Magna de abertura do curso de Ciências da Religião/UMESP, proferida em $22 / 2 / 2017$. 
Gostaria ainda de lembrar o título que dei a uma fala de abertura do Simpósio da ABHR e que retomo hoje, em parte: "Entre o voo da águia e o passo do elefante". $O$ desafio do Feminismo e do gênero ao estudo das religiōes. Esse título foi inspirado por um texto de Maria Cecília Minayo, em um livro de 2002: Caminhos do Pensamento. Epistemologia e Método. Nele, a autora discute os impasses colocados pelo contexto contemporâneo para o fazer ciência. Ao final, aponta uma, entre outras dificuldades colocadas para o campo científico: a resistência à mudança, à inovação, o temor ao desconhecido, "por convicção, conservadorismo ou comodismo" (p. 26). E termina com um desafio: "ou experimentamos voos de águia, ou nos contentamos com passos de elefante".

Quis trazer essa referência a Minayo, porque para os estudos acadêmicos da religião, no âmbito das Ciências Sociais, aí incluída a ciência da religião - e mais ainda no campo da Teologia -, a resistência à incorporação do pensamento feminista e das proposições teóricas e metodológicas trazidas pelo conceito de gênero, seja "por convicção, conservadorismo ou comodismo", expressam esse temor ao desconhecido e à mudança.

O feminismo - e o conceito de gênero - desafiam as pesquisas. Seguir os passos cadenciados e lentos, fincados na segurança do chão, como os elefantes, ou arriscar o voo das águias. O que queremos? O que escolhemos? É pensar a respeito disso que convido todas/os vocês esta tarde.

E cito a provocativa afirmação de Foucault:

Afinal, qual seria o valor da paixão pelo saber, se ela resultasse apenas num certo conhecimento... e não, de algum modo... num desregramento de si mesmo por parte do conhecedor? Há momentos na vida em que a questão de saber se se pode pensar de maneira diferente da que se pensa, e perceber de maneira diferente da que se enxerga, é absolutamente necessária, caso se pretenda de fato continuar a pensar e a refletir (Michel FOUCAULT. In: História da Sexualidade, v. 2: O Uso dos Prazeres, 7. ed. Rio de Janeiro: Edições Graal, 1984, p. 13).

Começo com algumas observações sobre as relações - sempre tensas - dos estudos de religião com algumas das propostas feministas.

Darlene Juschka (2001), professora do Programa de Women's and Gender Studies e do Departamento de Religious Studies na Universidade de Regina, no Canadá, ao referir à barreira da ciência aos estudos feministas, afirma serem os estudos de religião o campo em que se pode registrar a maior resistência. Mas cita também a Filosofia e a História. Segundo ela, apesar de pesquisadoras 
feministas das religiões haverem desenvolvido instrumentos teóricos e metodológicos de análise para o campo, estes permanecem ignorados ou conhecidos superficialmente por "estudiosos androcêntricos", como a autora os qualifica - ou desqualifica! E chama a atenção para o fato de ser o Feminismo uma crítica social e política, não vinculada a uma condição biológica, i.e., ao fato de se ser um homem ou uma mulher. Todas e todos podem ser feministas.

Para o Feminismo, o gênero, como construção social das diferenças sexuais, estas também socialmente construídas, atravessa e molda toda a realidade, inclusive a elaboração da ciência. Essa força de desconstrução do gênero pode ser, de fato, assustadora para a sociedade, mas de modo especial para as religiões do campo cristão.

Outra pesquisadora da religião, socióloga, faz observações semelhantes: Linda Woodhead (2001), professora no Departamento de Política, Filosofia e Religião na Lancaster University, Inglaterra, considerada, ao lado de Danièle Hervieu-Léger e Grace Davie uma das maiores especialistas contemporâneas em religião. Segundo a autora, a estrutura teórica dominante na Sociologia da Religião, especificamente, permanece gender-blind, cega, em relação às questões de gênero, isolando as pesquisas sobre mulheres e religião, ou de gênero, das consideradas "grandes questões sociológicas" nas análises da religião.

Ela enumera alguns dos avanços teóricos não incorporados aos estudos de religião: $O$ primeiro deles diz respeito à ideia da distinção entre "um 'sexo' biologicamente dado e um 'gênero' socialmente construído”. Estudos históricos, como o de Thomas Laqueur (1990), demonstram que o sexo varia histórica e culturalmente, havendo, na época moderna, uma profunda mudança na visão ocidental estabelecida de que há um único sexo, o macho, do qual a fêmea é uma manifestação inferior. A última, a concepção vigente no cristianismo, desde que Tomás de Aquino assumiu o pensamento de Aristóteles sobre os seres humanos. Vigente até hoje. Para o cristianismo, mulheres e homens são radicalmente distintos, cabendo aos homens o governo da sociedade, a política, o poder e a nós, mulheres, a reprodução de seres humanos, a domesticidade: "Belas, recatadas e do lar"!

É exatamente a proposição que pressupõe outra compreensão do que possa ser algo como uma "natureza humana" que faz tanto horror àqueles setores religiosos conservadores, em grande parte católicos e evangélicos, e os leva a condenarem o que denominam "a perniciosa ideologia de gênero", como vimos nos debates recentes sobre o PNE em nosso país. ${ }^{2}$

2 Cf. Rosado-Nunes, Maria José. A “ideologia de gênero” na discussão do PNE: a intervenção hierárquica católica. Horizonte. Belo Horizonte, v. 13, n. 39, p. 1.237-1.260, jul./set. 2015. 
Um segundo avanço teórico ao qual a SR é "cega" é aquele da rejeição à ideia da existência do masculino e do feminino como "duas esferas" distintas, separadas. Diz Woodhead (2007) - e eu cito: "Pesquisas psicológicas sobre as diferenças de sexo não conseguiram encontrar qualquer evidência em larga escala, ou universal de diferenças entre mulheres e homens (para um resumo, ver KIMMEL, 2000), e há uma crescente consciência de que em contextos culturais diversos o gênero pode ser visto como um ou como muitos, mais do que como binário". 3

Recentemente, em janeiro deste ano (2017), a revista National Geographic ${ }^{4}$ publicou um número dedicado todo ele à discussão sobre novas identidades e comportamento dos jovens do século XXI. O título do número é "A Revolução do Gênero". É significativo que uma revista de grande circulação como a NG proponha esse tema, o que pode ser tomado como indicador de mudança societária, cultural, em relação à compreensão de que há possibilidades múltiplas de realização dos seres humanos, quanto à sua sexualidade e ao que querem que os defina - ou não defina! Isto é, uma plasticidade enorme nas fronteiras entre os gêneros.

Simone de Beauvoir, lá pelos anos 40, já havia dito que "não se nasce mulher; torna-se". Mas, lembrando a polêmica em torno do exame do ENEM, em 2015, essa parece uma afirmação moralmente condenável, a ser banida das mentes jovens do Brasil, não é?!

Voltando a Linda Woodhead (2007), ela fala da crítica feminista à proposição de "papéis de sexos" diferenciados pela socialização na infância. As diferenças são continuamente negociadas no curso da vida. E a consequência dessa compreensão é que as pesquisas se dão em torno de "masculinities" _ "masculinidades" - e "feminities" - "feminilidades" - movendo a agenda de uma concentração sobre "mulheres" apenas. A autora trabalha também o conceito de secularização, caro aos estudos sociológicos das religiões na Modernidade, demonstrando o quanto seu conteúdo mudaria, se se tomasse em conta as formas pelas quais as mulheres se vinculam à religião: "Como sugerem as precedentes discussões, a atenção às implicações da religião no ordenamento e no desregramento das relações de gênero é capaz de produ-

\footnotetext{
Tradução da autora deste artigo.

4 National Geographic. Edição Especial: A revolução do Gênero - Novas identidades e comportamentos mudam a cara dos jovens do século 21, janeiro 2017, ano 17, no 2002.

5 Sobre essa polêmica, cf. http://www.revistaforum.com.br/2015/10/25/com-simone-de-beauvoir-enem-teve-questao-sobre-feminismo/ e https://www.cartacapital.com.br/sociedade/ simone-de-beauvoir-e-a-imbecilidade-sem-limites-de-feliciano-e-gentili-6444.html
} 
zir novos insights sobre o processo de secularização - e 'sacralização' - em contextos modernos".

Finalmente, se de um lado os estudos acadêmicos resistem à incorporação teórica de conceitos e propostas oriundas do Feminismo, de outro lado, feministas resistem criticamente às religiões, tidas como espaços por excelência da opressão das mulheres. Florence Rochefort (2004), por exemplo, historiadora, pesquisadora do CNRS - inicia um de seus textos com as seguintes palavras: "As religiões figuram entre os alvos da crítica feminista no Ocidente, no século XX - uma crítica militante tanto quanto acadêmica (savante, erudita) que revela muito particularmente, a diversidade de Feminismos". Face à hostilidade religiosa aos direitos e à autonomia das mulheres, ela reconhece três tipos de respostas feministas: aquelas "que abordam as religiões como instituições e poderes mas também como saberes e modos de regulação das "relações sociais de sexo" -, como as relações de gênero são nomeadas por grande parte das feministas na França; aquelas que rejeitam todo pensamento religioso como intrinsecamente patriarcal; e aquelas que reconhecem aspectos reacionários nas religiões a ser neutralizados, mas também a possibilidade de reforma das religiões pela mudança de suas doutrinas e práticas. A autora entende, portanto, práticas e discursos religiosos como ambíguos, assim como, suas normas, que nem sempre se espera que sejam cumpridas; ou pelo menos, sabe-se que não serão cumpridas.

Rochefort atribui ao maior ou menor grau de secularização da sociedade e de secularização interna às religiões a ênfase em uma dessas posições. Observa, no entanto, a existência de poucas pesquisas feministas que tomam a história do engajamento religioso das mulheres por seu objeto e a ausência de sistematização da crítica feminista à religião; observação que se aplica também ao Brasil.

Um debate interessante sobre as relações do Feminismo com as religiões aconteceu recentemente entre Elina Vuola, teóloga finlandesa, e a historiadora brasileira, Margareth Rago, no contexto de um Seminário internacional do Grepo, e pode ser lido no livro Gênero, feminismo e religião: Sobre um campo em constituição (2015).

\section{"Invisibilidade mútua" ou dois campos que "não se bicam"... mas têm muito em comum}

Depois dessa passagem bastante rápida, longe de qualquer pretensão exaustiva, pela resistência dos estudos de religião às concepções feministas e 
da resistência feminista às religiões, apresento a seguir alguns resultados de pesquisa desenvolvida com a $\mathrm{Dr}^{\mathrm{a}}$. Maria Teresa Citeli, no âmbito do GREPO (ROSADO, 2015). O interessante da pesquisa - um dos seus achados - é a aproximação - surpreendente - que estabelece entre o campo dos estudos de religião e aquele do Feminismo. Surpreendente, porque nossa pressuposição seria de que nada aproximaria campos tão distintos e até opostos. Porém, a pesquisa não os aproxima por seu conteúdo teórico, mas pela situação que enfrentam no campo acadêmico. Poderíamos falar, lembrando Max Weber, de uma afinidade não eletiva entre os dois campos, uma vez que essa "afinidade" resulta de constrangimentos externos.

Daí que se possa falar em uma invisibilidade mútua entre Religião e Feminismo, ou como "dois campos que não se bicam"... mas têm muito em comum. Para lembrar as ironias e jogos de linguagem do querido Flávio Pierucci.

Ainda que barreiras tenham sido rompidas, no caso do Brasil esses dois campos ainda se esforçam para sair da condição de desconhecidos pela grande teoria ou de outsiders na academia. É a partir dessa constatação que se pode interpretar a lacuna que impede encontros produtivos entre as duas áreas. Pesquisadoras/es da temática "gênero e religião" sublinham que estados da arte sobre a produção brasileira relativa às religiões não mencionam a temática de gênero, enquanto os balanços na área de estudos de gênero não contemplam a produção acadêmica no campo dos estudos de religião. É esse desconhecimento mútuo que denominamos "invisibilidade". ${ }^{6}$

Apesar dos impactos do Feminismo sobre as religiões - seja pelas mudanças provocadas nas práticas religiosas das mulheres, seja pela influência sobre a elaboração de um novo discurso - a Teologia Feminista - o desenvolvimento de uma análise feminista das religiões que tome em conta as diferentes formas pelas quais as relações entre os sexos moldam práticas, representações e discursos religiosos, é, no mínimo, bastante lento. Por sua vez, os estudos de religião não absorvem as proposições de gênero de maneira significativa e sistemática, como já vimos. Como entender as razões desse afastamento entre os dois campos?

Em um caminho distinto do tomado por Florence Rochefort, já citada, buscamos identificar possíveis convergências e divergências entre eles. Curiosamente, ao menos na trajetória acadêmica e de sua institucionalização, há mais aproximações do que poderia supor nossa vã filosofia.

${ }_{6}$ Um último balanço da área de Ciências Sociais (2010), no volume sobre Sociologia, apresenta um artigo a respeito de Sociologia da Religião, mas nada sobre gênero ou Feminismo. 
Uma delas diz respeito à época de surgimento dos estudos sociológicos sobre religião e das pesquisas feministas. Ambos emergiram na esfera acadêmica entre os anos 1950 e 1960. E ambos sofrem constrangimentos (fragilidades internas e rejeições externas) que representam potenciais ameaças à qualidade do conhecimento produzido e, portanto, à legitimidade e à possibilidade de integração acadêmica dos campos e de seus integrantes.

Outras aproximações expressam-se como dúvidas que perseguem insistentemente os estudos de religião e de gênero e as pesquisas de caráter feminista, ou de gênero, e, de certa forma, desqualificam-nos na academia. Vou apenas referir, sem maiores desenvolvimentos, em razão do tempo, três delas.

A primeira é a suspeita de que interesses religiosos ou militantes possam contaminar os resultados de pesquisas e ameaçar o prestígio acadêmico das áreas. Quer dizer, a afinidade que esses dois campos mantêm com questões formuladas fora dos limites estritamente acadêmicos, ou seja, que derivariam segundo essas críticas da prática religiosa ou do ativismo feminista e que atenderiam a interesses militantes ou pastorais. Ao reclamar do baixo grau de legitimidade científica das ciências sociais por parte das ciências "duras", Flávio Pierucci (1999) se pergunta: "o que dizer então desse obscuro e marginal ofício de sociólogo da religião?” Esse é o gancho para anunciar (ou denunciar) os riscos de perda da credibilidade científica da sociologia da religião provocados pelo enorme contingente - excessivo ou excessivamente tolerado, como ele afirma - de "interesses religiosos" disfarçadamente mobilizados por sociólogos que se mostram apegados demais ao valor da religião. No campo de estudos de gênero, não é muito diferente. Talvez atraia até mais incertezas que os estudos de religião, porque o interesse político de lutar contra desigualdades é (quase) sempre explicitado na área de gênero. É parte das propostas metodológicas feministas a explicitação de elementos contextuais que, explicitados ou não, direcionam também nossas escolhas de pesquisa: temas, interrogações que "merecem" ser pesquisados; quadro teórico escolhido; método da investigação...

Donna Haraway (2004, p. 211) expõe de maneira clara seu entendimento a respeito. Para ela: Gênero é um conceito desenvolvido para contestar a naturalização da diferença sexual em múltiplas arenas de luta. A teoria e a prática feminista em torno de gênero buscam explicar e transformar sistemas históricos de diferença sexual nos quais "homens" e "mulheres" são socialmente constituidos e posicionados em relações de hierarquia e antagonismo.

"Explicar e transformar." É o caso de lembrar Marx, em sua famosa Tese 11 sobre Feuerbach, a propósito da Filosofia: Não basta aos filósofos 
interpretar o mundo de formas diferentes; a questão é transformá-lo. Também no Brasil, pode-se ler em várias autoras a afirmação da pertinência dessa articulação entre pensamento e ação política.

Uma segunda dúvida que paira sobre os dois campos é a de que o exercício paralelo de atividade acadêmica e prática religiosa ou militante compromete o potencial de integração da área de estudos, na medida em que cria guetos ou "igrejinhas" fechadas entre seus pares, provocando isolamento e descrédito para as duas áreas de estudo. Dados preliminares de pesquisa realizada pelo GREPO mostram que o cuidado para evitar a compreensão das pesquisas no campo do gênero como restritas a pesquisadoras mulheres não impede que nós sejamos ainda ampla maioria na liderança de grupos de pesquisa. Aliás, a necessidade de evitar a formação de uma "panelinha" reunindo (exclusivamente) as interessadas na área de gênero esteve presente desde os anos 1970, como atesta um artigo intitulado: "Do limbo ao gueto" (COSTA et al., 1985).

A terceira dúvida expressa-se como uma certeza: a de que o uso de recursos provenientes de instituições não acadêmicas - igrejas e outras organizações - ameaça a credibilidade das pesquisas realizadas. (Discussão que não se limita, sabemos, a esses dois campos. É forte no campo da Medicina, das pesquisas financiadas por laboratórios; o que lembra o belo e triste filme $O$ Jardineiro Fiel.) A literatura brasileira sobre os estudos de religião e de gênero aponta que a institucionalização dessas áreas no mundo acadêmico dependeu da infraestrutura institucional e do capital material e simbólico de denominações religiosas, sobretudo a Igreja Católica para o avanço dos estudos das religiões, e do apoio financeiro continuado de agências internacionais de apoio à pesquisa e à ação, no caso de gênero. De fato, essa base de sustentação parece ter sido decisiva nos dois casos. A mesma pesquisa realizada pelo GREPO, já referida, contribui para exemplificar as diferentes ancoragens institucionais a que recorreram os estudos de religião e de gênero. Os resultados expõem os vínculos de grande parte dos programas de pós-graduação em ciências da religião com Instituições Superiores de Ensino (IES) de caráter confessional. A avaliação da CAPES 2013 registra dez programas de pós-graduação em Ciências da Religião, entre os quais sete estão vinculados a IES confessionais. Os três Programas mais antigos (implantados em 1978, 1979 e 1999); mais bem avaliados e que oferecem mestrado e doutorado funcionam em universidades religiosas: UMESP, PUC/SP e PUC/GO.

É intrigante notar que esses três traços de vulnerabilidade partilhada ao invés de promoverem certa sintonia, ao contrário, parecem causa de afastamento 
entre os estudos de religião e de gênero. De fato, somar precariedades poderia, à primeira vista, com toda a razão, potencializar os campos, o que não parece acontecer. Mas essa hipótese fica para futuras pesquisas.

\section{Considerações finais}

Caminhando para encerrar - já é hora - um toque mais diretamente feminista e político. Não poderia deixar de mencionar uma das mais perniciosas expressões contemporâneas de poder exercido contra as mulheres: as modalidades fundamentalistas das religiões. Trata-se de um problema de tamanha magnitude que o Parlamento Europeu promoveu, há alguns anos, pela primeira vez em sua história, uma reunião de parte de seus membros com especialistas internacionais a fim de examinar o impacto da religião na formulação de políticas públicas, nos níveis local, regional e mundial. "Este diálogo é entabulado no momento em que as instituições religiosas revelam um crescente interesse pela participação em debates acerca de políticas na Europa, mesmo quando a posição de algumas delas está em conflito com os valores que constituem o fundamento do consenso europeu em questões essenciais. Isso tem particular relevância no tocante aos direitos das mulheres e de homossexuais. Assim como no que se refere à sexualidade e à reprodução humana." A anfitrião italiana da reunião, Emma Bonino, concluiu: "A secularização das políticas constitui a única forma de construção de um mundo tolerante, um mundo em que as pessoas coexistam pacificamente".?

Não obstante, o novo contexto internacional, que vem nos últimos anos assumindo uma nova configuração, traz para o primeiro plano o ressurgimento de modalidades conservadoras e mesmo fundamentalistas de pensar e de agir, modalidades que, além de excludentes do ponto de vista econômico, têm cunho racista, patriarcal e repressivo. No caso da religião, essa situação tem efeitos cruciais sobre as mulheres. O sociólogo brasileiro Sérgio Paulo Rouanet (2001, p. 3), em artigo sobre os fundamentalismos islâmico, judaico e cristão, afirma: "Os três fundamentalismos têm em comum o tradicionalismo em questões morais e uma posição retrógrada quanto ao estatuto da mulher. São puritanos e misóginos".

Essa é a experiência de muitas mulheres religiosas. Elas oscilam entre a afirmação de sua fé religiosa e a necessidade de defender os mais elementares de seus direitos, em busca da própria autonomia. As mulheres exigem o reconhecimento de sua capacidade moral de tomar decisões que consideram válidas dos pontos de vista ético e religioso; o reconhecimento de seu direito de decidir acerca de questões que afetem suas vidas e seus corpos; e o reconhecimento de que sua experiência de vida é apropriada para a reflexão religiosa, em todas as áreas, mas

Cf. http://www.lchr.org/a/48/1v/articulos/actualidad/parlamento.html 
especialmente, na esfera da moral sexual e reprodutiva.

"Uma das principais reivindicações das mulheres", assinala Monique Dumais (Apud ROSADO NUNES, 1999, p. 295), "é ter o controle do próprio corpo. Como pode alguém sentir-se uma pessoa quando aquilo que se acha mais próximo dela, seu próprio corpo, lhe escapa, tornando-se dependente de outras pessoas e ficando submetido à autoridade destas?" Os corpos das mulheres têm sido o locus privilegiado de controle social e religioso dos homens sobre as mulheres. O discurso feminista contemporâneo, de caráter acadêmico ou político, religioso ou laico, tem buscado evidenciar as conexões existentes entre esse controle e a falta de direitos sociais, políticos e religiosos das mulheres. A efetivação da autonomia das mulheres - bem como, dos homens - não pode vir a ocorrer enquanto lhes forem negados direitos econômicos, sociais, políticos, e de controle sobre seus corpos, de autonomia na condução de suas vidas no campo da sexualidade e de sua capacidade reprodutiva.

Finalizo com uma provocação: Em relação à "novidade" trazida pelo Feminismo e pelos estudos de gênero, o campo de estudo das religiões pode voar como águia - para novos horizontes - ou amedrontar-se e caminhar no compasso do elefante.

\section{Referências}

COSTA, Albertina de Oliveira; BARROSO, Carmen; SARTI, Cynthia. Pesquisa sobre a mulher no Brasil: do limbo ao gueto? Cadernos de Pesquisa, Fundação Carlos Chagas, n. 54, p. 5-16, ago. 1985.

FOUCAULT, Michel. História da Sexualidade, v. 2: O Uso dos Prazeres, 7. ed. Rio de Janeiro: Edições Graal, 1984, p. 13.

HARAWAY, Donna. Gênero para um dicionário marxista. In: Cadernos Pagu. Campinas, n. 22, 2004, p. 201-246.

JUSCHKA, Darlene M. General Introduction. In: JUSCHKA, Darlene M. (Org.). Feminism in the Study of Religion: A Reader. New York: CONTINUUM, 2001.

LAQUEUR, Thomas W. (1990). Making Sex: Body and Gender from the Greeks to Freud. Cambridge, Mass.: Harvard University Press.

MARTINS, Carlos Benedito (coord.). Horizontes das ciências sociais no Brasil: sociologia. São Paulo: ANPOCS, 2010.

MINAYO, Maria Cecília de Souza; DESLANDES, Suely Ferreira (Orgs.). Caminhos do Pensamento: epistemologia e método. Rio de Janeiro: Editora Fiocruz, 2002.

National Geographic. Edição Especial: A revolução do Gênero - Novas identidades e comportamentos mudam a cara dos jovens do século 21, jan. 2017, ano 17, n. 2.002.

PIERUCCI, Antônio Flávio. Sociologia da Religião. Área Impuramente Acadêmica. In: S. Miceli (Org.). O que ler na Ciência Social brasileira (1970-1995), v. 2, Sociologia. São Paulo/ Brasília: Ed. Sumaré/ANPOCS. Brasília, DF: CAPES, 1999, p. 238. 
RAGO, Margareth. Comentários ao texto "Questões teóricas e metodológicas sobre gênero, feminismo e religião", de Elina Vuola. In: ROSADO, Maria José (Org.). Gênero, feminismo e religião: Sobre um campo em constituição, 1. ed. Rio de Janeiro: Garamond, 2015, p. 59-69.

ROCHEFORT, Florence. Contrecarrer ou interroger les religions. In: GUBIN, Eliane et al. (dirs.). Le siècle des féminismes. Paris: Les Éditions de l’Atelier/Éditions Ouvrières, 2004, p. 347.

ROSADO, Maria José et al. Aspectos da institucionalização dos Estudos da Religião e de Gênero no Brasil. In: Gênero, feminismo e religião: Sobre um campo em constituição, 1. ed. Rio de Janeiro: Garamond, 2015, p. 291-317.

ROSADO, Maria José (Org.). Gênero, feminismo e religião: Sobre um campo em constituição, 1. ed. Rio de Janeiro: Garamond, 2015.

ROSADO-NUNES, Maria José. A “ideologia de gênero” na discussão do PNE: a intervenção hierárquica católica. Horizonte. Belo Horizonte, v. 13, n. 39, p. 1.237-1.260, jul./set. 2015.

ROSADO NUNES, Maria Jose, Religion and Women's Rights: The Fundamentalist Face of Catholicism in Brazil. In: HOWLAND, Courtney (Org.). Religious Fundamentalisms and the Human Rights of Women. New York: St. Martin's Press, 1999.

ROUANET, Paulo Sérgio. Os três fundamentalismos. Folha de São Paulo, Caderno Mais, 21 de Outubro de 2001, p. 3.

VUOLA, Elina. Questões teóricas e metodológicas sobre gênero, feminismo e religião. In: ROSADO, Maria José (Org.). Gênero, feminismo e religião: Sobre um campo em constituição, 1. ed. Rio de Janeiro: Garamond, 2015, p. 39-57.

WOODHEAD, Linda. Gender Differences in Religious Practice and Significance. In: BECKFORD, James A., DEMERATH, N. J. (Orgs.). The SAGE Handbook of the Sociology of Religion. London: SAGE, 2007, p. 550-570.

Feminism and the Sociology of Religion: From Gender-blindness to Gendered Difference.

In: FENN, Richard K. The Blackwell Companion to Sociology of Religion. Oxford: Blackwell, 2001, p. 67-84.

\section{Sites consultados}

https://www.cartacapital.com.br/sociedade/simone-de-beauvoir-e-a-imbecilidade-sem-limites-de-feliciano-e-gentili-6444.html

http://www.lchr.org/a/48/1v/articulos/actualidad/parlamento.html

http://www.revistaforum.com.br/2015/10/25/com-simone-de-beauvoir-enem-teve-questaosobre-feminismo/

Submetido em: 8-5-2017

Aceito em: 19-07-2017 